\title{
Research on the Interaction of Inflation, Stock Price and Development Trend of Trading Volume
}

\author{
Zhiwei Shao \\ Xi'an Eurasia University, College of General Studies, Xi'an, Shaanxi, China, 710065
}

Keywords: stock price; trading volume; inflation

\begin{abstract}
The stock price index, consumer price index and the trading volume index are mutually causal, and the trading volume can be used as a leading indicator or early-warning indicator of the stock price to predict the future trend of stock price; in the long-term equilibrium model, there is negative correlation between stock price and inflation, and between trading volume and inflation; in the error correction model, trading volume is positive correlated with inflation and stock price, especially impacted largest by inflation. It shows that in the short run, the fluctuation of previous inflation will definitely bring about large fluctuation in current trading volume, which will be adjusted within a month with a ratio of 1.528, indicating that the trading volume strongly depends on inflation, followed by stock price.
\end{abstract}

The stock market is the "barometer" of the economy, and the leading indicator of the future performance of economic activity. Stock price reflects the forecasting of the company's future profit by investors to a certain extent, and the company's surplus depends on the prospect on enterprise's future operation status. [1] It is said that volume is the first before the price in the securities industry, which indicates that there is close relationship between trading volume and stock price. Specifically, when the volume is buy-in increase, the stock price is rising; when the volume is selling increase, the stock price is falling. [2] As the consumer price index keeps rising, the country will introduce monetary policy, and the corresponding policies will also act on the stock market, resulting in fluctuation in the stock index. On the one hand, the market will response to these macro policies introduced currently. On the other hand, the market also make appropriate expectations for future capital markets according to policies. The final result will be reflected in the trend of stock price index and trading volume. Inflation will be transmitted to the stock market through economic expectations. The occurrence of inflation will usually affect the confidence of economic entity in the future economy, and the loss of confidence will be immediately reflected in the stock market, resulting in more obvious negative sentiment and behavior. [3] Therefore, the development of China's future stock market, how to solve the economic problems brought by high inflation to capital market, and how to increase investors' investment confidence have become the problem focused on by government departments, financial departments and securities industry.

\section{Research Status}

With the continuous expansion of stock market in China, people have a new understanding of China's stock market, and the number of financial assets they hold is increasing, which results in great impact from the fluctuation of stock price on micro and macro economy. Therefore, the influence of the fluctuation on stock price inspires the research interest of many domestic scholars. According to actual situation, based on research methods of foreign scholars, new research results have been obtained, and the research vacancy in international field has been filled in. The research of economic scholars include two parts, research on the relationship between stock price as a part of asset price and macro economy status, and research on stock price and inflation respectively.

Due to the impact of financial crisis in 1997, there is high inflation rate in many Asian countries, except China. Chinese scholars have done a large quantity of research on this phenomenon. Zhao Xingqiu and Yu Cungao believe that there is negative correlation between inflation and stock price. [4] Liu Jinquan and Wang Fengyun conduct the least-square estimation with the fluctuation of stock 
returns as dependent variable, and the current and lagged value of fluctuation of inflation as independent variable, and empirically conclude that there is negative correlation. [5]

In recent years, many Chinese scholars have made further breakthroughs based on research of original stock price and trading volume relationship. Zhao Xiuheng, Li Shuangcheng and Liang Jianying draw conclusions, taking the price and trading volume of ten stocks on Shenzhen market as an example. First, the trading volume is positively correlated with stock price, and the trading volume in early period has a direct impact on the fluctuation of stock price in next period. Second, the trading volume influences changes of stock price, and vice versa. [6]

All the time, the relationship between trading volume and stock price is the hot research issue in financial field. The research conclusions can not only be suitable for stock market, also for financial and economic fields. In research of modern capital market, the relationship between trading volume and stock price is the focus of securities industry and the hotspot in academic research. Thus, the research on the relationship is full with important academic status and research value. [7-8]

\section{Basic Theories}

\subsection{Granger causality test}

Set $Y_{t}$ and $X_{t}$ are independent stationary time series processes, with $\mu_{1}, \mu_{2}$ as white noise. Consider,

$$
X_{t}=c_{1}+\sum_{j=1}^{p} \alpha_{j} X_{t-j}+\sum_{j=1}^{p} \beta_{j} Y_{t-j}+\mu_{1 t} \text { and } X_{t}=c_{1}+\sum_{j=1}^{p} \alpha_{j} X_{t-j}+\mu_{2 t}
$$

The statistics is calculated by Equation (1).

$$
G=\frac{(R S S(p)-R S S(q, p)) / q}{R S S(q, p) /(n-p-q-1)}
$$

There is a non-causal relationship between the two sequences, and the asymptotic follows distribution of $F(q, n-p-q-1)$ under large sample conditions, where, $R S S(q, p), R S S(p), n$ is the residual sum of squares and sample size of the above two OLS estimations. If $G \geq F_{\alpha}(q, n-p-q-1)$, reject the null hypothesis $H_{0}: \beta_{j}=0(\forall j)$, and accept the alternate hypothesis $H_{1}: \beta_{j} \neq 0(\exists j)$. Thus, $Y_{t}$ is the Granger cause of $X_{t}$. [9-11]

\subsection{Co-integration analysis}

If a time series has to undergo a $d$ difference before it becomes a stable sequence, the sequence is said to be a $d$ order integrated, which is recorded as $I(d)$. If a set of sequences $Y(t), X_{1}(t), X_{2}(t), \cdots \cdots, X_{k}(t)$ are all $d$ order integrated, here $b>0, \alpha=\left(a_{0}, a_{1}, a_{2}, \cdots \cdots, a_{k}\right)$, $X(t)=\left(Y(t), X_{1}(t), X_{2}(t), \cdots, X_{k}(t)\right)^{\prime}$ the set of sequences is considered to be $(d, b)$ order co-integrated. [12]

\subsection{Autoregressive distributed lag model and error correction model}

Autoregressive distributed lag model is shown in Equation (2).

$$
Y(t)=\beta_{0}+\sum_{i=1}^{m} \delta_{i} Z(t-i)+\sum_{i=1}^{n} \gamma_{i} Y(t-i)+\varepsilon_{t} \quad \varepsilon_{t} \sim N\left(0, \sigma^{2}\right)
$$

It reflects the long-term development trend of the explained variable, and also reflects the intensity of the influence of the long-term development trend of the explained variable, indicating that the control of the explained variable can be controlled by controlling the explanatory variable. [12] 


\subsection{Error correction model}

$$
\triangle Y(t)=\tilde{\beta}_{0}+\sum_{i=1}^{m} \tilde{\delta}_{i} Z(t-i)+\sum_{i=1}^{n} \tilde{\gamma}_{i} Y(t-i)+k \operatorname{ecm}(t-1)+\varepsilon_{t} \quad \varepsilon_{t} \sim N\left(0, \sigma^{2}\right)
$$

In Equation (3), ecm $=\hat{Y}(t)-b_{0}-\sum_{l=1}^{k} b_{l} X_{l}(t)$ comes from long-term equilibrium equation of sequence $\hat{Y}(t)=b_{0}+\sum_{l=1}^{k} b_{l} X_{l}(t)$. The fluctuation of the explained variable in the model can be divided into two parts: long-term equilibrium and short-term fluctuation. Each difference term reflects the influence of short-term fluctuations of variables. [13]

\section{The Analysis on the Interaction of Stock Price, Trading Volume and the Development Trend of Inflation}

According to the Shanghai Composite Index indicator and the setting of China's macroeconomic indicators, the trading volume (VOL) and stock price $(S P)$ in the Shanghai Composite Index from February 2008 to September 2017 are selected as the research objects, and the important indicator of inflation and consumer price index (CPI) are selected for comprehensive analysis. Firstly, this paper analyzes the causal relationship between stock price, trading volume and inflation development, then constructs the cointegration relationship of the three, and finally establishes the dynamic system model of the development trend of trading volume and its influencing factors.

\subsection{Granger causality test of stock price $(S P)$, trading volume (VOL), and consumer price index $(C P I)$}

When the second-order difference of $V O L$ is in the first-order lag, and the residual sequence is in the first-order lag, $\mathrm{ADF}=-5.472<-2.384$ and it is a stationary sequence at 0.05 in the confidence level.

$$
G=\frac{(R S S(p)-R S S(q, p)) / q}{R S S(q, p) /(n-p-q-1)}=5.742>F_{0.05}(2,59)=3.21 \text {, so } S P \text { is the Granger cause of } V O L \text {. In }
$$

the same way, it is also the Granger cause of CPI . [14-15]

Table 1

\begin{tabular}{cccccccc}
\hline & $\begin{array}{c}\text { Confidence } \\
\text { level }\end{array}$ & stability & $\begin{array}{c}\text { Lag } \\
\text { phase }\end{array}$ & P & $G$ & $F$ & result \\
\hline VOL & 0.05 & Stationary & $/$ & $/$ & $/$ & $/$ & $/$ \\
SP & 0.05 & stationary & 3 & 0.006 & 5.742 & $F(2,59)$ & cause \\
CPI & 0.05 & stationary & 2 & 0.003 & 6.324 & $F(2,60)$ & cause \\
\hline
\end{tabular}

\subsection{The co-integration test of $S P, V O L$ and $C P I$}

Johansen test is used according to the co-integration theory. The maximum eigenvalue test shows that there are three co-integration equations at the $5 \%$ level, shown in Table 2; the eigenvalue trace test shows that there are three co-integration equations at the $1 \%$ level (Table is not shown in this paper).

The test levels are judged at 0.05 and 0.01 respectively, because the maximum eigenvalue statistic test has $71.79>29.79,25.72>15.49,2.32<3.84$; therefore, there are three cases with intercept and trend items between the three variables, and three long-term co-integration equations. 
Table 2 The co-integration test of VOL, SP and CPI

\begin{tabular}{|c|c|c|c|c|}
\hline \multicolumn{5}{|c|}{ Trend assumption: Linear deterministic trend } \\
\hline \multicolumn{5}{|c|}{ Lags interval (in first differences): 1 to 1} \\
\hline \multicolumn{5}{|c|}{ Unrestricted Cointegration Rank Test } \\
\hline Hypothesized & & Max-Eigen & 5 Percent & 1 Percent \\
\hline No. of CE(s) & Eigenvalue & Statistic & Critical Value & Critical Value \\
\hline None $* *$ & 0.68 & 71.79 & 29.79 & 35.46 \\
\hline At most $1 * *$ & 0.44 & 25.72 & 15.49 & 19.94 \\
\hline At most $2 * *$ & 0.05 & 2.32 & 3.84 & 6.65 \\
\hline
\end{tabular}

\subsection{Empirical analysis on the interaction of $S P, V O L$ and $C P I$}

In order to further explain the relationship between $S P, V O L$ and $C P I$, according to the Granger causality of the three, the appropriate lag order is selected to establish their quantitative relationship, to determine their respective econometric models. [16-17]

\subsubsection{Autoregressive distributed lag average model of $V O L$ and $S P$}

$$
\begin{gathered}
\mathrm{VOL}_{t}=0.405 \mathrm{VOL}_{t-1}+7.486 S P_{t}-7.131 S P_{t-1}+60.399-0.787 \mathrm{MA}(1) \\
R^{2}=0.789, \quad D . W .=2.308, \text { Loglikelihood }=-187.326, \quad A I C=9.158, \quad S C=9.365, \\
T=[5.816,7.416,-8.265,6.737,-8.256]
\end{gathered}
$$

\subsubsection{Autoregressive lag sliding model of $V O L, S P$ and $C P I$}

$$
\begin{gathered}
\mathrm{VOL}_{t}=0.392 \mathrm{VOL}_{t-1}+8.026 S P-7.438 S P_{t-1}+0.519 C P I_{t-1}-0.633 A R(1) \\
R^{2}=0.747, \text { D.W. }=2.307, \text { Loglikelihood }=-135.836, \text { AIC }=9.309, S C=9.518, \\
T=[5.559,8.683,-9.342,3.357,-4.819]
\end{gathered}
$$

\subsubsection{Long-term equilibrium model of $V O L, S P$ and $C P I$}

$$
\begin{gathered}
\mathrm{VOL}_{t}=427.80+9.221 S P-8.127 S P_{t-1}-3.118 C P I_{t}-0.452 M A(1) \\
R^{2}=0.666, D . W .=2.057, \text { Loglikelihood }=-191.774, A I C=9.597, S C=9.806, \\
T=[3.604,8.388,-2.962,-7.901,-2.879] .
\end{gathered}
$$

\subsubsection{Error correction model of $V O L, S P$ and $C P I$}

$$
\begin{gathered}
\nabla V O L_{t}=0.133 \nabla V O L_{t-1}-0.072 \nabla V O L_{t-2}+6.709 \nabla S P_{t-1}+2.057 \nabla S P_{t-2}+18.816 \nabla C P I_{t-1} \\
-2.544 \nabla C P I_{t-2}-1.528 e c m 1-0.262 e c m 2
\end{gathered}
$$$$
R^{2}=0.623, \text { Loglikelihood }=-191.517, \text { Akaike AIC }=9.976, \quad \text { SchwarzSC }=10.31362
$$

The models show that, $e c m 1=V O L_{t-1}+3.875 C P I_{t-1}-500.646$. If $V O L$ at $t-1$ is greater than the long-term equilibrium solution $-3.875 C P I+500.646$ and the error correction term ecm 1 is positive, then -1.528 ecm 1 is negative, causing the decrease of $\nabla V O L$. If $V O L$ at $t-1$ is less than the long-term equilibrium solution $-3.875 C P I+500.646$, then ecm 1 is negative, then -1.528 ecm 1 is positive, causing the increase of $\nabla V O L$; If $S P$ at $t-1$ is greater than the long-term equilibrium solution $-1.800 C P I+223.240$ and the error correction termecm 2 is positive, then -0.262 ecm 2 is negative, causing the decrease of $\nabla V O L$; if $S P$ at $t-1$ is less than the long-term equilibrium solution $-1.800 C P I+223.240$ and the error correction term ecm 2 is negative, then -0.1528 ecm 2 is positive, causing the increase of $\nabla V O L$, thus reflecting the control of long-term non-equilibrium 
error on $V O L_{t}$. In the short-term non-equilibrium model, the resilience of $V O L_{t-1}, V O L_{t-2}, S P_{t-1}$, $S P_{t-2}, C P I_{t-2}$, and $C P I_{t-2}$ of $V O L_{t}$ are $0.133,-0.072,6.709,2.057,18.816$, and -2.444, respectively, indicating that in the short term, there is a positive correlation between $V O L$ and $C P I$ and $S P$, most affected by CPI. It indicates that in the short term, the previous fluctuation of $C P I$ will inevitably bring about a large degree of fluctuation in $V O L$ in the current period, and also indicates that there is a strong dependence for VOL on CPI. Such fluctuations will be adjusted within a month with a ratio of $1.528 \mathrm{ecm} 1$ coefficient, followed by $S P$.However, the fluctuation of $S P$ in the previous period will also cause fluctuation of $V O L$, ecm2 indicating that $S P$ and the $C P I$ long-term equilibrium model will be adjusted within a ratio of 0.262 within one month to affect the fluctuation of $V O L$ in short term.

\section{Conclusion}

Based on the econometric theory of causal theory, autoregressive distribution lag model and error correction model, this paper reveals the relationship of development and control between stock price, trading volume and inflation, and draws some conclusions. First, stock price index ( $S P$ ), consumer price index ( $C P I)$ and trading volume index (VOL) are mutually causal, and the trading volume can be used as a leading indicator or early-warning indicator of stock price to predict the future trend of stock price. Second, in the long-term equilibrium model, there is negative correlation between stock price index and consumer price index, and the trading volume index and consumer price index, that is, the increase of $C P I$ leads to the decrease of $S P$ and $V O L$, indicating that during the period of high inflation, the consumer price index decreases, conductive to the healthy development of China's stock market. Third, the autoregressive lag model of the three shows that the three are conductive. As long as one variable changes, more or less will cause changes of the other two variables, and the previous index directly affects the trend of the later index. Fourth, in the error correction (short-term fluctuation) model, VOL is positively correlated with $C P I$ and $S P$, and the increase in stock price or the increase in CPI index will lead to an increase in trading volume; In the short term, in order to ensure the steady development of the stock market, the increase or decrease of $V O L, S P$ and $C P I$ should meet a suitable ratio, and also indicate that there is a strong dependence for $V O L$ on $C P I$, followed by $S P$, and the coefficient ecm1 and ecm 2 indicate the equilibrium of $V O L$ and $C P I$, and the equilibrium of $S P$ and $C P I$, will fluctuate in the short-term non-equilibrium at a ratio of 1.528 and 0.262 . This fluctuation will be adjusted within one month to reflect the control of the non-equilibrium error on $V O L_{t}$.

\section{Acknowledgements}

This work is supported by Education Department of Shaanxi Provincial Government Project, Research on Problems in Shaanxi Vocational Education Reform and Development, Project No. 17JK1034; and school-level project, Research on Modular Teaching in Mathematics of Engineering Courses, Project No. 2018YB011.

\section{References}

[1] Long Jianwei, Cai Ruhai. Analysis of relationship between stock price and inflation from the perspective of currency policy [J], Social Sciences in Ningxia, 2008,(5):47-53.

[2] Kong Shanghui. Empirical Research on the Price-Volume Relation of China's Stock Market [D]. Qingdao University, 2009.

[3] Zhu Baoliang. The Impact of Current Inflation on Economy [J]. China Finance, 2011,(11):60-61.

[4] Zhao Xingqiu, Yu Cungao. Empirical Research on the Relationship between Inflation, Output 
and Stock Price [J]. Statistical Research, 1999(s1),1-6.

[5] Liu Jinquan, Wang Fengyun. A Positive Analysis of the Dynamic Relationship between Stock Returns and Inflation [J]. Journal of Finance and Economics, 2004(1),123-128.

[6] Zhao Xiuheng, Li Shuangcheng, Liang Jianying. Study on the Dynamic Relation of Volume and Price in China Stock Market [J]. Mathematics in Practice and Theory, 2004,34(12):58-61.

[7] Du Yongguang. Research on the Relationship between Stock Price, Inflation and Trading Volume [D]. Xi'an University of Architecture and Technology, 2009.

[8] Andrew W Lo, Jiang Wang. Trading Volume: Implications of An Intertemporal Capital Asset Pricing Model.[D].1050 Massachusetts Avenue Cambridge, 2001.

[9] He Zongln. Maekawa Koichi. On spurious Grange Causality [J]. Economic Letter, 2001,(73)307-313.

[10] Johansen S., Juseliusk. Maximun likelihood estimation and inference on cointegration with applications to the demand for money [J].Oxford Bull.Econ.Stat.1990,52-55.

[11] Shao Zhiwei. Research on Development Trend and Influencing Factors of Investment on Xi'an Real Estate Development Based on BACE [J].Advances in Engineering Research. 2018, (152):352-358.

[12] Li Zinai, Pan Wenqing. Econometrics [M]. Beijing: Higher Education Press, 2006, December.

[13] Zhou Jian,Li Zinai. Theory, Method and application of Macro-economical Statistical Data Diagnosis [M].Beijing, Tinghua university press. 2005, 37-65.

[14] Granger C W J. Testing for causality: A personal viewpoint [J], Economic Dynamics and Control. 1980, (2):329-352.

[15] Li Shuzhong, Li Tianzhong, Ding Tao. Empirical Research on the Relationship of Agricultural Products Futures Price Index and CPI [J]. Journal of Financial Research, 2006,(11):103-115.

[16] Feng Wenquan, Mao Qi. Technology of Economic Forecast and Decision-making [M]. Wuhan: Wuhan University Press, 2007, July.

[17] Zhang Xiaodong. A Guide to Using EViews [M]. Beijing: China Machine Press, 2006, October. 